\title{
ON THE LAYER OF RELATIVELY LOW WAVE VELOCITY AT A
} DEPTH OF ABOUT 80 KILOMETERS*

\author{
By B. Gutenberg
}

\section{INTRODUCTION}

MoRE THAN twenty years ago, the author (Gutenberg, 1926) pointed out that the longitudinal waves of shallow earthquakes decrease considerably in amplitude at epicentral distances between a few (say 2) degrees and about 15 degrees. At greater distances the amplitudes become again rather large, at $16^{\circ}$ epicentral distance about as large as at $2^{\circ}$. With further increase in epicentral distance the amplitudes decrease slowly. The whole phenomenon was interpreted as due to a decrease in wave velocity at a depth between 70 and $80 \mathrm{~km}$. Further investigations (Gutenberg and Richter, 1931; 1935, pp. 335--343; $1939 a$; Gutenberg, $1945 a ; 1945 c$, pp. 126-127) indicate that the decrease in velocity must be rather small, that the shadow zone is less significant in earthquakes which start at a depth of 150 to $250 \mathrm{~km}$. and is absent in earthquakes originating at a depth of more than about $300 \mathrm{~km}$.

It was pointed out by Gutenberg $(1928,1945 a)$ that all the findings can be explained on the assumption that at a critical depth of about $80 \mathrm{~km}$. the melting point of the material is reached. There has been no clear indication thus far whether the decrease in velocity is gradual over a certain depth interval or sudden at a certain depth, or both.

The present paper is a first attempt to find more accurately this decrease in wave velocity with increasing depth.

\section{Materials Used for P Waves}

A number of earthquakes (table 1) were investigated which had epicentral distances of between $4^{\circ}$ and $25^{\circ}$ from the Pasadena group of stations. For a few of them, records from Tucson were available (by courtesy of the United States Coast and Geodetic Survey). Most epicenters, origin times, and magnitudes of shocks were taken from an unpublished book by Gutenberg and Richter on the seismicity of the earth. Errors in the assumed distances (it is probable that they rarely exceed one degree, and usually they do not exceed half a degree) are probably less attributable to the fact that the older travel-time curves were used in these determinations, and that the Pasadena group of stations was included, as to lack of data in southerly and westerly azimuths from the epicenters. Differences in structure, and of velocity, in the upper layers certainly play some role, too. All times of clear phases were measured, as well as amplitudes and periods of $\mathrm{P}$ and $\mathrm{S}$.

\footnotetext{
* Manuscript received for publication December 11, 1947.
} 
TABLE 1

Observed Travel Times of $\mathbf{P}$

$(\mathrm{R}=$ region $[\mathrm{a}=$ Lower California, Gulf of California; $\mathrm{b}=$ Central Mexico and off Central Mexico; $\mathrm{c}=$ off northern California; $\mathrm{d}=$ Montana; $\mathrm{e}=$ off British Columbia]; Pas. $=$ Pasadena; Mt. W. = Mount Wilson; Riv. = Riverside; S. Bar. = Santa Barbara; La $J .=$ La Jolla; Hai. = Haiwee; Tin. = Tinemaha; Pal. = Palomar; Tuc. = Tucson.)

\begin{tabular}{|c|c|c|c|c|c|c|c|c|c|c|c|}
\hline \multirow{2}{*}{ No. } & \multirow{2}{*}{$\begin{array}{l}\text { Date of shock } \\
\text { and (below) } \\
\text { origin time } \\
\text { (h.: min.: sec.) }\end{array}$} & \multirow{2}{*}{$\mathrm{R}$} & \multicolumn{9}{|c|}{ Distance (degrees) and (below) travel time of $P$ (min: sec) at } \\
\hline & & & Pas. & Mt. W. & Riv. & s. Bar. & La J. & Hai. & Tin. & Pal, & Tue. \\
\hline 1 & $\begin{array}{l}1931 \text {, Oct. } 1 \\
11: 45: 38\end{array}$ & a & $\begin{array}{l}4.3 \\
1 \cdot 07\end{array}$ & & & & & & & & $\cdots$ \\
\hline 2 & $\begin{array}{l}1932, \text { July } 7 \\
16: 15: 51\end{array}$ & a & $\begin{array}{l}6.5 \\
1: 35\end{array}$ & $\ldots$ & $\ldots$ & $\ldots$ & $\ldots$ & $\ldots$ & ... & $\cdots$ & $\ldots$ \\
\hline 3 & $\begin{array}{l}1933, \text { Jan. } 4 \\
21: 10: 46\end{array}$ & a & $\begin{array}{l}9.3 \\
2: 17\end{array}$ & $\ldots$ & ... & & & & . & ... & $\ldots$ \\
\hline 4 & $\begin{array}{l}1932, \text { July } 12 \\
19: 24: 10\end{array}$ & a & $\begin{array}{l}10.4 \\
2: 31\end{array}$ & ... & ... & ... & ... & ... & & ... & ... \\
\hline 5 & $\begin{array}{l}1931 \text {, Aug. } 16 \\
11: 40: 23\end{array}$ & a & $\begin{array}{l}12.3 \\
2: 56\end{array}$ & $\ldots$ & $\ldots$ & ... & ... & $\cdots$ & ... & ... & ... \\
\hline 6 & $\begin{array}{l}1939, \text { May } 2 \\
13: 14: 47\end{array}$ & a & $\begin{array}{l}6.4 \\
1: 34\end{array}$ & $\ldots$ & $\begin{array}{l}5.8 \\
1: 25\end{array}$ & $\begin{array}{l}7.5 \\
1: 54\end{array}$ & $\begin{array}{l}4.8 \\
1: 14\end{array}$ & $\begin{array}{l}8.0 \\
1: 58\end{array}$ & $\begin{array}{l}8.9 \\
2: 11\end{array}$ & ... & .. \\
\hline 7 & $\begin{array}{l}\text { 1941, Mar. } 15 \\
05: 46: 23\end{array}$ & a & $\begin{array}{l}7.1 \\
1: 42\end{array}$ & ... & $\begin{array}{l}6.5 \\
1: 36\end{array}$ & $\begin{array}{l}8.2 \\
?\end{array}$ & $\begin{array}{l}5.6 \\
?\end{array}$ & $\begin{array}{l}8.8 \\
2: 05\end{array}$ & $\begin{array}{l}9.6 \\
2: 21\end{array}$ & $\ldots$ & $\ldots$ \\
\hline 8 & $\begin{array}{l}\text { 1945, June } 27 \\
13: 08: 20\end{array}$ & a & $\begin{array}{l}9.3 \\
2: 18\end{array}$ & $\begin{array}{l}9.4 \\
2: 19\end{array}$ & $\begin{array}{l}8.9 \\
2: 12\end{array}$ & $\begin{array}{l}10.5 \\
2: 34\end{array}$ & $\begin{array}{l}7.9 \\
1: 58\end{array}$ & $\begin{array}{l}10.9 \\
2: 40\end{array}$ & $\begin{array}{l}11.8 \\
2: 53\end{array}$ & ... & . \\
\hline 9 & $\begin{array}{l}\text { 1934, Sept. } 15 \\
06: 56: 46\end{array}$ & b & $\begin{array}{l}18.4 \\
4: 20\end{array}$ & & & $\ldots$ & $\ldots$ & $\ldots$ & $\ldots$ & $\cdots$ & ... \\
\hline 10 & $\begin{array}{l}\text { 1932, Dec. } 7 \\
16: 22: 09\end{array}$ & b & $\begin{array}{l}19.8 \\
4: 33\end{array}$ & $\ldots$ & $\ldots$ & $\ldots$ & $\ldots$ & $\ldots$ & & $\ldots$ & $\ldots$ \\
\hline 11 & $\begin{array}{l}\text { 1933, Dec. } 13 \\
21: 23: 45\end{array}$ & b & $\begin{array}{l}19.8 \\
4: 28\end{array}$ & $\ldots$ & $\ldots$ & $\ldots$ & $\ldots$ & $\ldots$ & $\ldots$ & $\ldots$ & $\cdots$ \\
\hline 12 & $\begin{array}{l}\text { 1933, Apr. } 9 \\
\text { 03:58:17 }\end{array}$ & b & $\begin{array}{l}18.9 \\
4: 23\end{array}$ & $\ldots$ & $\ldots$ & $\ldots$ & $\cdots$ & $\ldots$ & & & $\ldots$ \\
\hline 13 & $\begin{array}{l}\text { 1933, July } 10 \\
03: 22: 04\end{array}$ & b & $\begin{array}{l}19.7 \\
4: 32\end{array}$ & $\ldots$ & $\ldots$ & $\ldots$ & $\cdots$ & $\ldots$ & $\ldots$ & $\ldots$ & $\ldots$ \\
\hline 14 & $\begin{array}{l}\text { 1934, Jan. } 28 \\
19: 10: 03\end{array}$ & b & $\begin{array}{l}23.9 \\
5: 16\end{array}$ & $\ldots$ & $\ldots$ & $\ldots$ & $\cdots$ & $\cdots$ & $\cdots$ & & $\ldots$ \\
\hline 15 & $\begin{array}{l}\text { 1931, Jan. } 2 \\
09: 49: 02\end{array}$ & $\mathrm{~b}$ & $\begin{array}{l}18.0 \\
4: 13\end{array}$ & $\ldots$ & $\ldots$ & $\ldots$ & $\ldots$ & $\ldots$ & $\ldots$ & & $\ldots$ \\
\hline 16 & $\begin{array}{l}\text { 1934, Nov. } 30 \\
02: 05: 10\end{array}$ & b & $\begin{array}{l}19.4 \\
4: 29\end{array}$ & & & & & & & $\ldots$ & $\ldots$ \\
\hline 17 & $\begin{array}{l}\text { 1932, June } 3 \\
10: 36: 50\end{array}$ & b & $\begin{array}{l}19.1 \\
4: 25\end{array}$ & & $\ldots$ & & $\ldots$ & $\ldots$ & & $\ldots$ & \\
\hline 18 & $\begin{array}{l}1943, \text { Feb. } 22 \\
09: 20: 45\end{array}$ & b & $\begin{array}{l}22.2 \\
5: 00\end{array}$ & $\begin{array}{l}22.2 \\
5: 01\end{array}$ & $\begin{array}{l}21.7 \\
4: 54\end{array}$ & $\begin{array}{l}23.4 \\
5: 12\end{array}$ & $\begin{array}{l}20.8 \\
4: 46\end{array}$ & 23.6 & $\begin{array}{l}24.4 \\
5: 23\end{array}$ & $\begin{array}{l}20.8 \\
4: 47\end{array}$ & 16.9 \\
\hline 19 & $\begin{array}{l}\text { 1935, June } 29 \\
06: 48: 54\end{array}$ & b & $\begin{array}{l}20.4 \\
4: 37\end{array}$ & $\begin{array}{l}20.4 \\
4: 38\end{array}$ & & $\ldots$ & $\ldots$ & $\begin{array}{l}21.8 \\
4: 52\end{array}$ & $\begin{array}{l}22.6 \\
5: 01\end{array}$ & $\ldots$ & $\ldots$ \\
\hline
\end{tabular}


Table 1-Continued

\begin{tabular}{|c|c|c|c|c|c|c|c|c|c|c|c|}
\hline \multirow{2}{*}{ No. } & \multirow{2}{*}{$\begin{array}{l}\text { Date of shock } \\
\text { and (below) } \\
\text { origin time } \\
\text { (h.: min.: sec.) }\end{array}$} & \multirow{2}{*}{$\mathrm{R}$} & \multicolumn{9}{|c|}{ Distance (degrees) and (below) travel time of $\mathrm{P}(\mathrm{min}: \mathrm{sec})$ at } \\
\hline & & & Pas. & Mt. W. & Riv. & S. Bar. & $\mathrm{La} \mathrm{J}$. & Hai. & Tin. & Pal. & Tuc. \\
\hline \multirow[t]{2}{*}{20} & 1941, Apr. 15 & $\mathrm{~b}$ & 20.2 & 20.3 & 19.7 & 21.4 & 18.7 & 21.7 & 22.6 & & 15.2 \\
\hline & $19: 09: 54$ & & $4: 38$ & $4: 37$ & $4: 32$ & $4: 50$ & $4: 23$ & $4: 53$ & $5: 00$ & & $3: 37$ \\
\hline \multirow[t]{2}{*}{21} & 1943, May 25 & b & 19.3 & 19.4 & 18.8 & 20.5 & 17.9 & $\ldots$ & 21.7 & $\ldots$ & $\ldots$ \\
\hline & $10: 31: 30$ & & $4: 28$ & $4: 28$ & $4: 22$ & $4: 40$ & $4: 11$ & & $4: 55$ & & \\
\hline \multirow[t]{2}{*}{22} & 1945, June 30 & $\mathrm{~b}$ & 17.2 & 17.3 & 16.8 & 18.3 & 15.8 & 19.9 & 20.8 & $\ldots$ & 15.9 \\
\hline & $05: 31: 18$ & & $4: 08$ & $4: 10$ & $4: 05$ & $4: 15$ & $3: 51$ & $4: 32$ & $4: 42$ & & $3: 51$ \\
\hline \multirow[t]{2}{*}{23} & 1932, June 6 & $c$ & 8.4 & $\ldots$ & $\ldots$ & 7.4 & 9.8 & $\ldots$ & 6.1 & $\ldots$ & $\ldots$ \\
\hline & $08: 44: 22$ & & $2: 00$ & & & $1: 52$ & $2: 26$ & & $1: 36$ & & \\
\hline 24 & $\begin{array}{l}\text { 1934, July } 6 \\
22: 48: 52\end{array}$ & $\mathrm{c}$ & $\begin{array}{l}9.2 \\
2: 15\end{array}$ & & $\ldots$ & $\ldots$ & 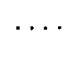 & & $\ldots$ & $\ldots$ & \\
\hline \multirow[t]{2}{*}{25} & 1941, Feb. 9 & $\mathrm{c}$ & 8.7 & & 9.2 & $\ldots$ & 10.3 & 7.5 & 6.8 & & \\
\hline & $09: 44: 04$ & & $2: 09$ & & $2: 17$ & & $2: 34$ & $1: 53$ & $1: 42$ & & \\
\hline \multirow[t]{2}{*}{26} & 1941, Oct. 3 & $\mathrm{c}$ & 8.4 & & 8.9 & & 10.0 & 7.2 & 6.5 & $\ldots$ & $\cdots$ \\
\hline & $16: 13: 08$ & & $2: 03$ & & $2: 12$ & & $2: 20$ & $1: 44$ & $1: 34$ & & \\
\hline \multirow[t]{2}{*}{27} & 1945, Sept. 28 & $\mathrm{c}$ & 9.9 & 9.9 & 10.4 & & & 8.5 & 7.7 & & 15.4 \\
\hline & $22: 24: 10$ & & $2: 24$ & $2: 24$ & $2: 30$ & & & $2: 25$ & $2: 00$ & & $3: 42$ \\
\hline \multirow[t]{2}{*}{28} & 1935, Oct. 19 & $\mathrm{~d}$ & 13.3 & 13.2 & 13.2 & & & 11.4 & 10.6 & & \\
\hline & $04: 48: 03$ & & $3: 14$ & $3: 14$ & $3: 15$ & & & $2: 48$ & $2: 37$ & & \\
\hline \multirow[t]{2}{*}{29} & 1935, Oct. 31 & $d$ & 13.3 & 13.2 & 13.2 & & & 11.4 & 10.6 & $\ldots$ & \\
\hline & $18: 37: 49$ & & $3: 16$ & $3: 15$ & $3: 12$ & & & $2: 48$ & $2: 37$ & & \\
\hline \multirow[t]{2}{*}{30} & 1929, Sept. 17 & $\mathrm{e}$ & 19.0 & $\ldots$ & $\ldots$ & $\ldots$ & & $\ldots$ & $\ldots$ & $\ldots$ & $\cdots$ \\
\hline & $19: 17: 34$ & & $4: 25$ & & & & & & & & \\
\hline \multirow[t]{2}{*}{31} & 1935, Sept. 24 & e & 17.8 & & & & & & 15.2 & & \\
\hline & $22: 12: 15$ & & $4: 19$ & & & & & & $3: 38$ & & \\
\hline \multirow[t]{2}{*}{32} & 1945, Aug. 2 & $\mathrm{e}$ & 22.2 & 22.2 & 22.6 & & & 21.0 & $\ldots$ & 22.7 & \\
\hline & $20: 44: 45$ & & $4: 59$ & $4: 59$ & $5: 04$ & & & $4: 41$ & & $5: 11$ & \\
\hline \multirow[t]{2}{*}{33} & 1939, July 18 & $\mathrm{e}$ & 16.8 & $\cdots$ & 17.3 & 16.3 & 18.4 & 15.4 & 14.4 & $\ldots$ & \\
\hline & $03: 26: 38$ & & $4: 00$ & & $4: 05$ & $3: 53$ & $4: 18$ & $3: 41$ & $3: 28$ & & \\
\hline \multirow[t]{2}{*}{34} & 1946, June 23 & $\mathrm{e}$ & 16.4 & 16.3 & 16.7 & 15.7 & 17.8 & 14.5 & 13.5 & 17.3 & $\ldots$ \\
\hline & $17: 13: 22$ & & $3: 51$ & $3: 51$ & $3: 55$ & $3: 44$ & $4: 10$ & $3: 30$ & $3: 17$ & $4: 06$ & \\
\hline
\end{tabular}

In figure $1 \dagger$ the observed times for $\mathrm{P}$ minus 14 times the distance $\Delta$ in degrees are plotted as a function of distance, and in figure 2 the amplitudes of $\mathrm{P}$ which would have been found for a shock of magnitude 7 with periods of $P$ of one second. Figure 1 also contains the calculated travel time curves of JeffreysBullen (1940) and observed curves of Gutenberg-Richter (1934). Both were drawn by their respective authors on the assumption that the travel-time curve of $\mathrm{P}$ is continuous. Actually, the newly observed travel times as well as the amplitudes indicate the presence of at least two branches with distinctly different apparent velocities. They intersect near $\Delta=17^{\circ}$. The smaller

$\dagger$ Figures were drafted by Mr. John M. Nordquist. 


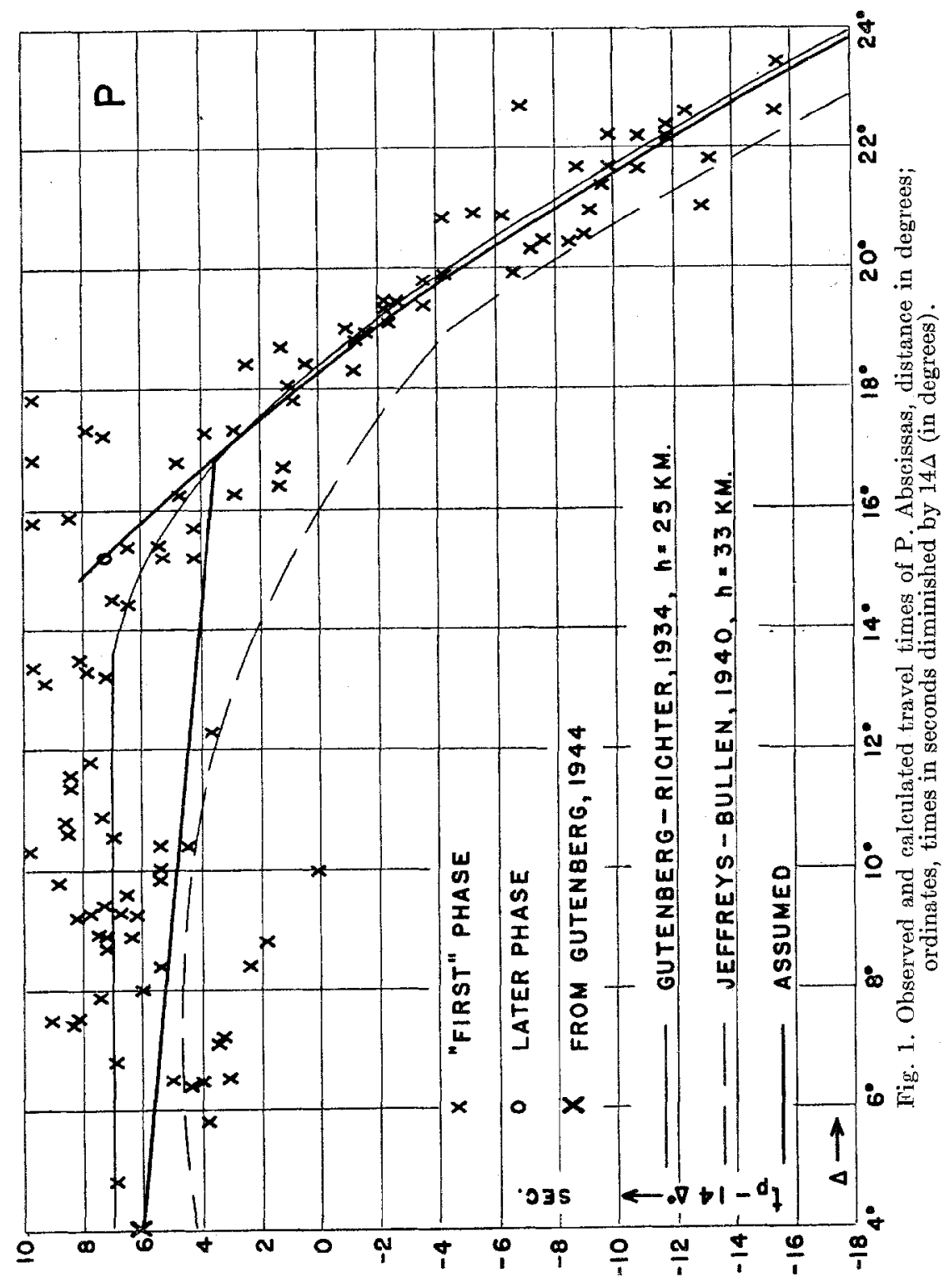




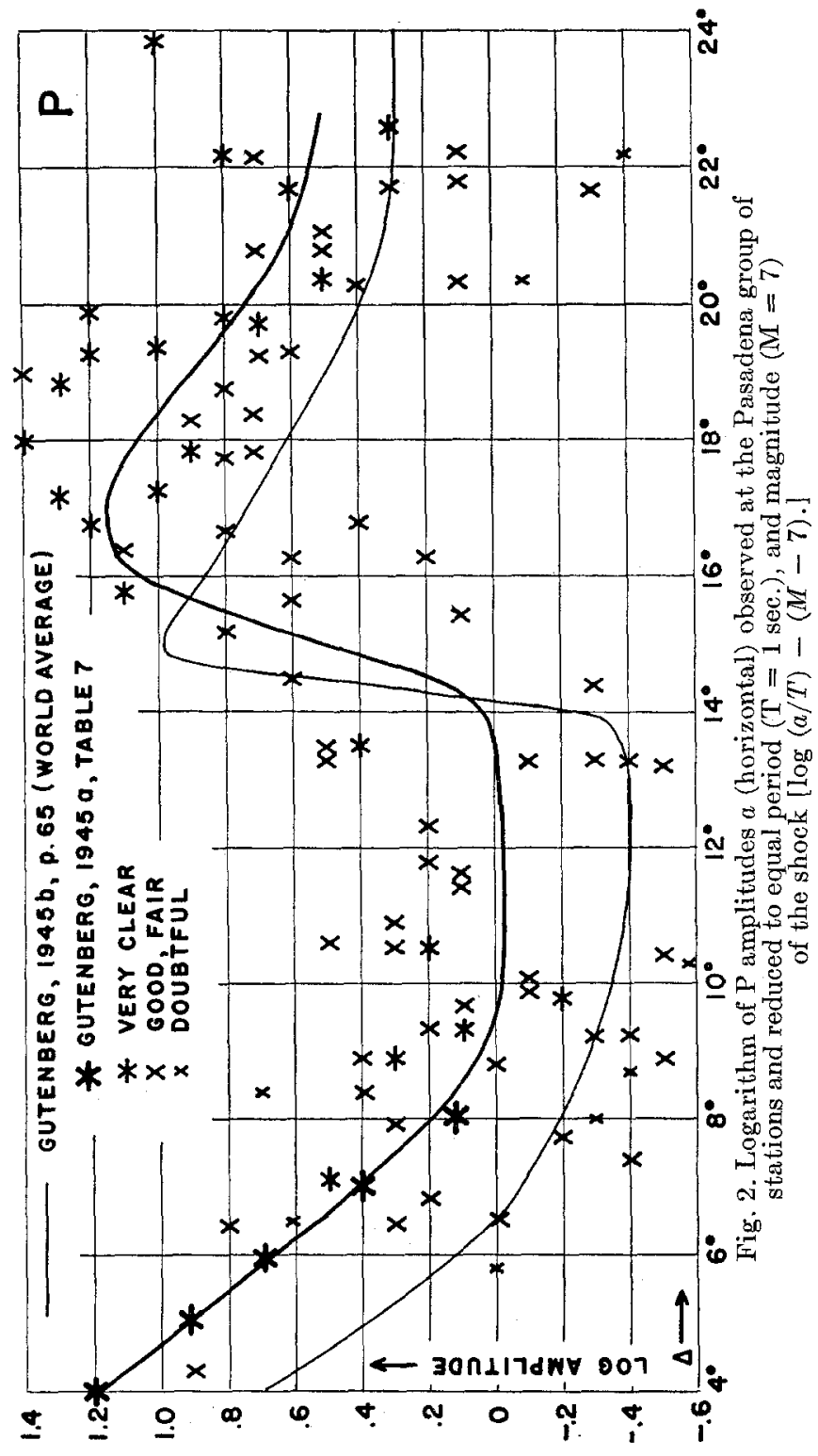


absolute values of the Jeffreys-Bullen curve are mainly due to the fact that they were calculated for a focal depth of $33 \mathrm{~km}$., which was also assumed to be the thickness of the continental surface layers (depth of the Mohorovičic discontinuity; Jeffreys-Bullen, 1940, p. 5 resp. p. 4). The focal depth of all or most of the earthquakes used in the present study is probably less than $33 \mathrm{~km}$.; most California earthquakes seem to have a depth of about $18 \mathrm{~km}$. Assuming this value, the Jeffreys-Bullen travel times would be about 2 sec. greater.

TABLE 2

Assumed Travel Trmes $t$ of P for the Pacific Coastal Regron of North America ( $\bar{V}=$ resulting apparent velocity; $i_{0}=$ angle of incidence at the surface for $\left.V_{0}=5.58 \mathrm{~km} / \mathrm{sec}.\right)$

\begin{tabular}{|c|c|c|c|c|c|}
\hline \multicolumn{2}{|c|}{ First branch } & \multicolumn{4}{|c|}{ Second branch } \\
\hline$\underset{\text { (deg.) }}{\Delta}$ & 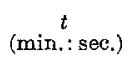 & $\underset{\text { (deg.) }}{\Delta}$ & $\left.{ }_{\left(\min _{.}: \mathrm{t}\right.}^{t} \mathrm{sec}.\right)$ & $\begin{array}{c}\bar{V} \\
\left(\mathrm{~km} / \mathrm{sec}_{.}\right)\end{array}$ & $\sin i_{0}$ \\
\hline 4 & $1: 02.1$ & 15 & $3: 37.6$ & 9.2 & 0.61 \\
\hline 5 & 15.9 & 16 & 49.6 & 9.4 & 59 \\
\hline 6 & 29.7 & 17 & $4: 01.3$ & 9.6 & 58 \\
\hline 7 & 43.4 & 18 & 12.8 & 9.7 & 57 \\
\hline 8 & 57.2 & 19 & 24.1 & 9.9 & 56 \\
\hline 9 & $2: 11.0$ & 20 & 35.2 & 10.1 & 55 \\
\hline 10 & 24.8 & 21 & 46.0 & 10.3 & 54 \\
\hline 11 & 38.6 & 22 & 56.6 & 10.6 & 53 \\
\hline 12 & 52.4 & 23 & $5: 07.0$ & 10.8 & 52 \\
\hline 13 & $3: 06.2$ & 24 & 17.2 & 11.1 & 50 \\
\hline 14 & 20.0 & 25 & 27.1 & 11.3 & 49 \\
\hline 15 & 33.8 & 26 & 36.8 & 11.6 & 48 \\
\hline 16 & 47.6 & & & & \\
\hline
\end{tabular}

Table 2 gives travel times of $\mathrm{P}$ waves which were finally adopted and on which the following calculations are based. Figure 1 indicates that the first segment of the observed travel-time curve for $P$ waves extending to about $17^{\circ}$ corresponds to an almost constant apparent velocity of about $8 \mathrm{~km}$. per second; the second branch starts with an apparent velocity of about $9 \mathrm{~km}$. per second, which increases rather rapidly with increasing distance. At distances of less than $15^{\circ}$ amplitudes are very small. This may explain the many late observations. At $\Delta=4^{\circ}$ the curve corresponds to the well-established curve for Pn in California shocks (Gutenberg, 1944a, table 9). At epicentral distances of about $15^{\circ}$ to $17^{\circ}$ some seismograms show a small beginning followed by a larger impulse (fig. 3). It was assumed that the small beginning belongs to the first branch of the travel-time curve, which probably corresponds to a diffracted 
wave ( $t$ proportional to $\Delta$ ), and that the first larger impulse corresponds to the second branch.

Neither figure 1 nor figure 2 indicates that for the shocks of table 1 in western North America there is any other intersection of two branches of the travel-time curve between $17^{\circ}$ and the largest distance, of about $25^{\circ}$.

Since the magnitude of deep-focus earthquakes has been defined (Gutenberg, $1945 \mathrm{c}$ ), it is now possible to use the records of near-by deep-focus earthquakes recorded at the Carnegie station at Huancayo, Peru, for qualitative results. Quantitative data have been listed previously (GutenbergRichter, 1939a, with seismograms; Gutenberg, 1945a, p. 303). Only the records of the horizontal Wenner seismographs were used. Amplitudes and periods of $\mathrm{P}$ were measured and displacements calculated, and the resulting values of $A=M-\log$ $(a / T)$ for direct longitudinal waves were plotted in figure 4. ( $M=$ magnitude determined from distant stations, $a=$ horizontal ground amplitude of $\mathrm{P}$ in microns,

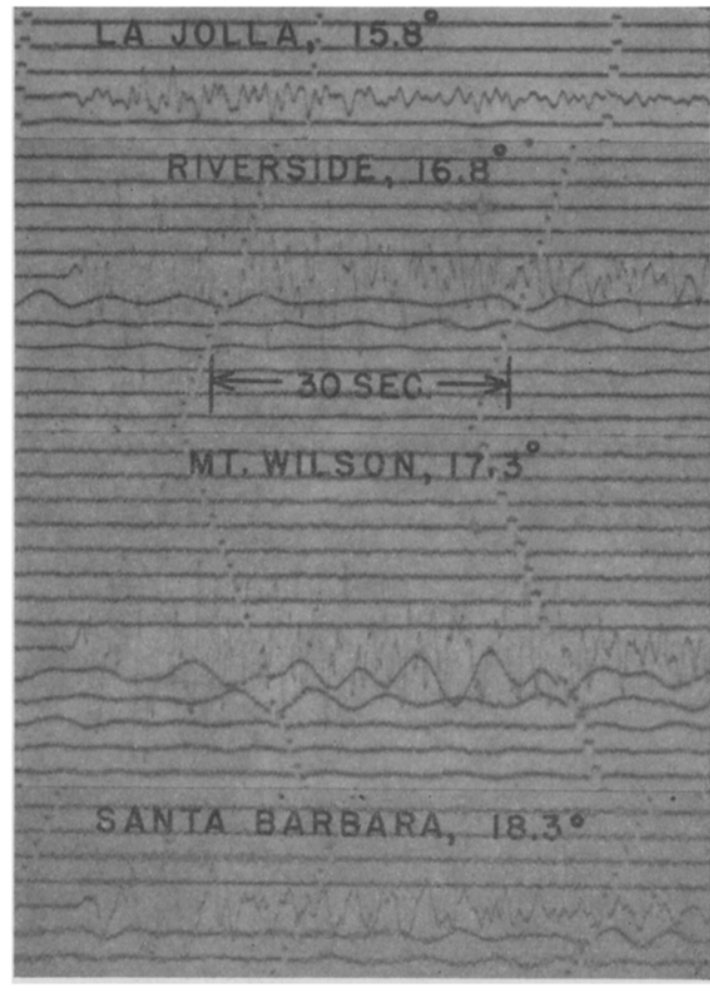

Fig. 3. P phases recorded at the Pasadena group of stations from shock no. 22, 1945, June 30, magnitude $63 / 4$, off Mexico, on Benioff short-period verticals. The magnification of the instruments differs considerably at the various stations, but all other constants are the same. $T=$ period corresponding to a.) Many records used previously could not be included in the present research since the magnitudes of the corresponding shocks could not be determined with sufficient accuracy. Figure 4 shows, in addition, approximate curves for $A$. For a shock of magnitude 7 , with periods of one second in $\mathrm{P}, \log a=7$ - $A$; inside the area surrounded by $A=7$, the amplitude of $\mathrm{P}$ is smaller than 1 micron under these conditions; for $A<6$, the amplitudes then would be more than 10 microns. Amplitudes near the lines $A=51 / 2$ are 100 times those near $A=71 / 2$, if other conditions are the same. 


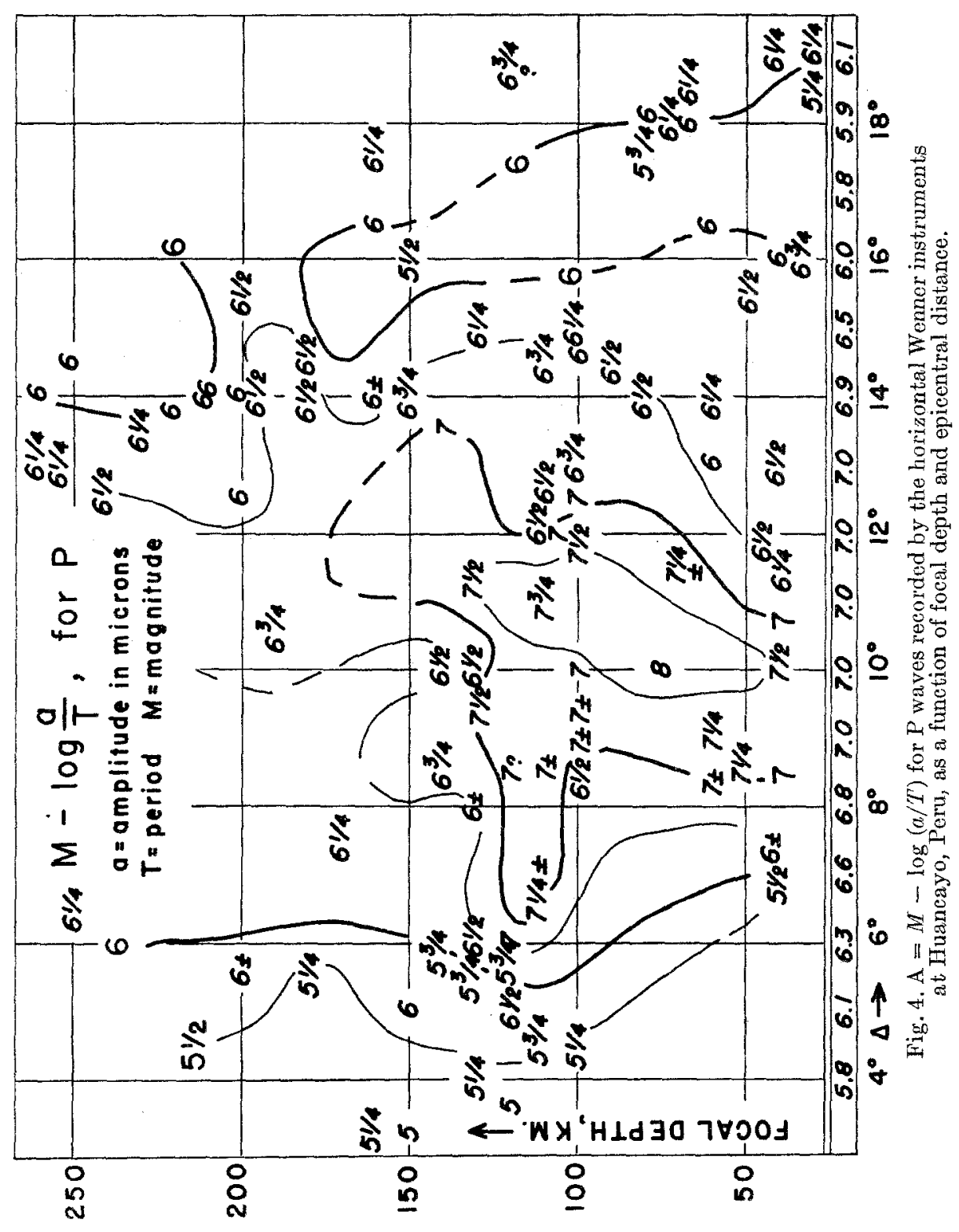


The data represented in figure 4 are affected by errors in the determination of (1) the magnitude of the shocks, (2) the epicentral distance of Huancayo, (3) the ground amplitude of the $\mathrm{P}$ waves, (4) their period, especially if this is small, and (5) the focal depth. Most of the details in the curves of equal values of $A$ have no significance. If one compares figure 4 with the figure previously given by Gutenberg (1945c, p. 126), which was based on data from various regions (many of them from Japanese stations), such possible errors must be considered. In both figures, the area with maximum $A$ (minimum amplitudes of $\mathrm{P}$ ) is found near $\Delta=10^{\circ}, h=80$ to $100 \mathrm{~km}$., and agrees fairly well. However, the decrease in amplitudes toward this minimum seems to be much greater in the region near Huancayo than in the average. Corresponding values of $A$ for shallow shocks near the Pacific coast of North America (from table 2) have been added at the bottom of figure 4 . They agree much better with the old figure (Gutenberg, 1945c) and the data from average shallow shocks (Gutenberg, 1945b, p. 65) than with the data from Huancayo in figure 4. Such differences are probably real and due to the difference in crustal structure. Small changes in the velocity-depth curve, especially in the layer of small velocity, have rather large effects on the amplitudes. On the other hand, the increase in amplitudes of $\mathrm{P}$ (decrease in $A$ ) as the focal depth increases to more than $200 \mathrm{~km}$. is similar in all areas from which data were available. Thus, the fact of the layer with relatively low velocity for $P$ at a depth of about $100 \mathrm{~km}$. and the increase in the velocity of $\mathrm{P}$ below $200 \mathrm{~km}$. seems rather general.

\section{Methods Used}

The problem of finding details concerning a decrease in velocity with depth is difficult because no waves arrive at the surface of the earth which had their maximum depth within the low-velocity layer (for sketches, see Gutenberg and Richter, 1939, fig. 3, p. 535). In order to simplify the calculation, only such assumptions were made concerning the decrease of velocity with depth which lead to relatively simple calculations for travel times and distances. It was very soon found that the conditions which must be fulfilled by these depthvelocity curves permit only relatively small variations in the rate and amount of decrease of velocity with depth. The major conditions are: first, the travel times calculated under the specific assumptions must agree with the observed times; and second, the end of the shadow zone must come out at an epicentral distance of about $15^{\circ}$.

The simplest assumption is that, going downward, the wave velocity decreases suddenly at a depth of about $80 \mathrm{~km}$. and then gradually increases below. In another group of assumptions, it is taken that the velocity remains constant below the Mohorovičic discontinuity (about $40 \mathrm{~km}$. deep in California) down to a given depth, then decreases gradually in a layer of the thickness $d$ below, and increases gradually again at still greater depths. For the 
decrease, several assumptions have been made. First, it was assumed that the equation $V=a+b z$, which is very useful in applied seismology, holds within the layer of decreasing velocity; $b$ (negative) and $a$ are constants, $z$ is the depth. This assumption leads to simple equations as long as the curvature of the layers involved can be neglected. It gives, therefore, an approximation under actual conditions. If the curvature of the layers is introduced, the equations become very complicated. The assumption $V=a+b r^{2}$ leads to complicated equations (Jeffreys, 1939) and was not used.

Relatively simple equations for the travel time and distance as a function of the angle of incidence result if $V=a r^{n}$ (Mohorovičić, 1910; Bullen, 1945; $\mathrm{Fu}, 1947$ ), especially with $n=1$ and $n=2$.

\section{THEORY}

For the calculations, the travel times given in table 1 were reduced to those for the depth of $40 \mathrm{~km}$. by taking as usual the approximate equations (neglecting the curvature of the earth and assuming that the focus is at the bottom of the first layer):

$$
\sin i: \sin i_{0}=V: V_{0} \text {. }
$$

First layer: $\delta \Delta=d \tan i$

deeper layers: $\delta \Delta=2 d \tan i$

$$
\delta t=d / V \cos i
$$

$$
\delta t=2 d / V \cos i
$$

where $\delta \Delta$ is the reduction in distance, $\delta t$ the reduction in time, $d$ the thickness of the layer, and $V$ the (constant) velocity. The following values were used (Gutenberg, 1944b, p. 140):

$$
\begin{array}{lll}
d_{1}=18 \mathrm{~km} . & V_{1}=5.58 \mathrm{~km} / \mathrm{sec} . ; & d_{2}=15 \mathrm{~km} . \quad V_{2}=6.03 \mathrm{~km} / \mathrm{sec} . \\
d_{3}=7 \mathrm{~km} . & V_{3}=6.91 \mathrm{~km} / \text { sec. } ; & V_{4}=8.00 \mathrm{~km} / \mathrm{sec} .
\end{array}
$$

The use of the approximate equations (1), (2), and (3) is permissible, since the total of the angular distances in the upper $40 \mathrm{~km}$. is in general less than $1^{\circ}$. The resulting travel times for waves starting from and arriving at a depth of $40 \mathrm{~km}$. are given in table 3 . They were used under all assumptions.

In any case, it was assumed that below $40 \mathrm{~km}$. the velocity remains constant to a depth $d_{1}$, then decreases to a depth $d_{2}$, then increases again. The travel time $\delta t$ and the angular distance $\delta \theta$ corresponding to the two paths (down and up) between $d_{1}$ and $d_{2}$ were calculated. These values were subtracted from the corresponding values in table 2 , and a new travel-time curve for rays starting and ending at a depth $d_{2}$ was found. This curve had to be completed by assuming values for distances smaller than about $15^{\circ}$. However, owing to the fact that the shadow zone must come out as indicated above, and that the slope of 
the travel-time curve (apparent velocity) at $\Delta=0^{\circ}$ is given, only small variations are possible. Finally, by use of the Wiechert-Herglotz method, the velocity as a function of depth was found in each case.

TABLE 3

Assumed Travel Times $t$ for Longitudinal Waves Starting and Ending at a Deptr of $40 \mathrm{Km}$. With an ANGLe of InCidence $i$ (Assumtng $V=8.00 \mathrm{KM} / \mathrm{sec}$.).

$(\bar{V}=$ apparent velocity)

\begin{tabular}{c|c|c|c||c|c|c|c}
\hline \hline $\begin{array}{c}\Delta \\
(\mathrm{deg} .)\end{array}$ & $\begin{array}{c}t \\
(\mathrm{~min} . \mathrm{sec} .)\end{array}$ & $\begin{array}{c}\bar{V} \\
(\mathrm{~km} / \mathrm{sec} .)\end{array}$ & $\sin i$ & $\begin{array}{c}\Delta \\
(\mathrm{deg} .)\end{array}$ & $\begin{array}{c}t \\
(\min . \mathrm{sec} .)\end{array}$ & $\begin{array}{c}\overline{\bar{V}} \\
(\mathrm{~km} / \mathrm{sec} .)\end{array}$ & $\sin i$ \\
\hline 15 & $3: 30.0$ & 9.0 & 0.89 & 21 & $4: 37.9$ & 10.3 & 0.77 \\
16 & 41.9 & 9.3 & 86 & 22 & 48.4 & 10.6 & 75 \\
17 & 53.5 & 9.5 & 84 & 23 & 58.7 & 10.8 & 74 \\
18 & $4: 04.9$ & 9.7 & 82 & 24 & $5: 08.7$ & 11.1 & 72 \\
19 & 16.1 & 9.9 & 81 & 25 & 18.5 & 11.4 & 70 \\
20 & 27.1 & 10.1 & 79 & 26 & 28.1 & 11.6 & 69 \\
\hline
\end{tabular}

Assumption (a): $\quad V=a-b z$

Neglecting the curvature of the earth (and consequently only approximately),

$$
\begin{aligned}
& \delta \Delta=F\left(\cos i_{2}-\cos i_{1}\right) / \sin i_{2} \\
& \delta t=D+E\left(\log \cos i_{2} / 2-\log \cos i_{1} / 2\right)
\end{aligned}
$$

where

$$
D=(4.605 / b) \log \left(V_{1} / V_{2}\right) ; \quad E=9.210 / b ; \quad F=2 V_{2} / b .
$$

Calculations were made on the assumption $d_{1}=40 \mathrm{~km}$., $d_{2}=100 \mathrm{~km}$, $V=8.00-0.004(z-40)$. Then $\sin i_{2}=0.97 \sin i_{1} ; D=15.0, E=2303$; $F=35.2$. The resulting (approximate) velocities as a function of depth are given in table 5 .

General equations considering the effect of the curvature of the earth.

$$
\delta \Delta=2 r_{1} \int_{r_{1}}^{r_{2}} \frac{\tan i}{r} d r \quad \delta \theta=2 \int_{r_{1}}^{r_{2}} \frac{\tan i}{r} d r
$$

$\delta \Delta$ is the distance, measured over the surface of the sphere with the radius $r_{1}$, and $\delta \theta$ is the angular distance, both corresponding to the two paths, up and down.

$$
\delta t=2 \int_{r_{1}}^{r_{2}} \frac{d r}{V \cos i}
$$


At the end of the shadow zone $\left(\Delta=\Delta^{*}\right)$

$$
\left(\frac{\partial(\delta \Delta)}{\partial \sin i}\right)_{i=i^{*}}=-\left(\frac{\partial \Delta_{2}}{\partial \sin i}\right)_{i=i^{*}}, \quad \text { where } \quad \Delta=\Delta_{2}+\delta \Delta
$$

General assumption: $\quad V=a r^{n}$

In this case:

$$
\begin{aligned}
\sin i & =p a r^{n-1}=a p(V / a)^{\frac{n-1}{n}} \quad \text { where } \quad p=\left(r_{1} \sin i_{1}\right) / V_{1} \\
d r & =\cos i d i /(n-1) p a r^{n-2}=r \cot i d i /(n-1) \\
d r / V & =p \cos i d i /(n-1) \sin ^{2} i
\end{aligned}
$$

Introduction of the value of $d r$ in (8) and of $d r / V$ in (9) leads to

$$
\begin{aligned}
& \delta \theta=2\left(i_{2}-i_{1}\right) /(n-1) \quad \delta \Delta=2 r_{1}\left(i_{2}-i_{1}\right) /(n-1) \\
& \delta t=2 p\left(\cot i_{1}-\cot i_{2}\right) /(n-1)
\end{aligned}
$$

For $n \geqq 1$ the wave paths (rays) are parts of spirals which approach asymptotically the center of the earth. If $n=0$, the velocity is constant. $n=1$ is a singular case; the angle of incidence $i$ is constant along the ray (logarithmic spiral) and the integrals in (8) and (9) are to be taken over $d r / r$. In the present paper the equations were used for $n=0, n=1$, and $n=2$.

$$
\begin{gathered}
\text { Assumption }(b): \quad n=1 ; \quad V=a r ; \quad \sin i=a p \\
\delta \Delta=4.6052\left(\log r_{1}-\log r_{2}\right) r_{1} \tan i \\
\delta t=4.6052\left(\log r_{1}-\log r_{2}\right) / a \cos i=\delta \theta / a \sin i
\end{gathered}
$$

$V$ was assumed constant from $r=6,330$ to $r_{1}=6,320 \mathrm{~km}$. As the velocity $V_{1}=8.00$ at the depth $r_{1}$ is given, $a$ can be calculated from (15); it follows that $\log a=7.1024-10$. The only unknown quantity is $r_{2}$, the depth at which the decrease in velocity ends. Equation (10) leads to

$$
r_{1}-r_{2}=d=-\left[\frac{\cos ^{3} i_{1}}{2} \frac{\partial \Delta_{2}}{\partial \sin i_{1}}\right]_{i=i^{*}}, \Delta \text { in km . }
$$

where $i$ is only approximately known, and $\Delta_{2}$ can be calculated only after $d$ has been assumed. It was found that, approximately, $\cos i_{1}{ }^{*}=0.43 ;\left(\partial \Delta_{2} / \partial \sin i_{1}\right)^{*}$ 
$=-1,650 \mathrm{~km}$.; hence a decrease in velocity in a layer approximately $d=66$ $\mathrm{km}$. thick should produce in this case the observed shadow zone.

Equation (15) corresponds to the limit $d V / d r=V / r$, for which an actual shadow zone begins to exist. For any smaller rate of decrease in $V$ with $r$, no actual shadow zone (with observed amplitudes from diffracted waves only) occurs, but a zone with direct waves of rather small amplitudes. The actual observations may be explained under either assumption. Unfortunately, seismograms from the critical distance are scarce; should instances with unusually

TABLE 4

Calculated Travel Times $(t, \theta)$ of Waves, Starting and Arriving at a Depth of $50 \mathrm{KM}$, Assumption $(b)$.

\begin{tabular}{|c|c|c|c|c|c|}
\hline $\begin{array}{c}\theta_{2} \\
\text { (deg.) }\end{array}$ & $\left(\begin{array}{c}\delta \theta \\
(\operatorname{deg} .)\end{array}\right.$ & (deg.) & $\stackrel{t_{2}}{(\min .: \text { sec.) }}$ & $\stackrel{\delta t}{(\min .: \mathrm{sec} .})$ & ${ }_{(\min .: \text { sec.) }}^{t}$ \\
\hline 2 & 28.3 & 30.3 & $0: 28$ & $6: 26$ & $6: 54$ \\
\hline 4 & 14.0 & 18.0 & $0: 55.5$ & $3: 15$ & 4:10 \\
\hline 6 & 10.4 & 16.4 & $1: 23.1$ & $2: 26.5$ & $3: 49.6$ \\
\hline 8 & 7.3 & 15.3 & $1: 50.4$ & $1: 42.0$ & $3: 32.4$ \\
\hline 9 & 6.1 & 15.1 & $2: 04.0$ & $1: 25.7$ & $3: 29.7$ \\
\hline 10 & 5.0 & 15.0 & $2: 17.4$ & $1: 11.2$ & $3: 28.6$ \\
\hline 11 & 4.2 & 15.2 & $2: 30.7$ & $1: 00.7$ & $3: 31.4$ \\
\hline 12 & 3.2 & 15.2 & $2: 43.8$ & $0: 47.6$ & $3: 31.4$ \\
\hline 13 & 2.4 & 15.4 & $2: 56.5$ & $0: 36.2$ & $3: 32.7$ \\
\hline 15 & 1.8 & 16.8 & $3: 20.6$ & $0: 29.3$ & $3: 49.9$ \\
\hline 17.5 & 1.5 & 19.0 & $3: 49.5$ & $0: 25.9$ & $4: 15.4$ \\
\hline
\end{tabular}

large amplitudes near $15^{\circ}$ be observed in the future, the probability would be stronger for a shadow zone bounded outside by a ring with the properties of a caustic.

For the calculations it was assumed that $r_{1}=6,320 \mathrm{~km}$.; $r_{2}=6,260 \mathrm{~km}$; $\log a=7.1024-10 ; V_{1}=8.00 \mathrm{~km} /$ sec.; $V_{2}=7.925 \mathrm{~km} / \mathrm{sec} . ; \theta_{2}=1^{\circ}$ corresponds to $109.2 \mathrm{~km}$.; $\delta \theta=1.09 \tan i_{0}$ in degrees; $\delta t=15.09 / \cos i ; r_{1} / r_{2}=$ 1.0096. Resulting velocities are again given in table 5 . Resulting values for the travel-time curve starting and ending at the level of $50 \mathrm{~km}$. (using $\theta=\theta_{2}+\delta \theta$; $t=t_{2}+\delta t$ ) are given in table 4 . They present a typical example of the effect of the low-velocity layer in producing the shadow zone. The original data started with $\Delta=15^{\circ}, t=3: 29.6$, and included $\Delta=19^{\circ}, t=4: 15.9$.

Assumption (c): $n=2 ; \quad V=a r^{2}$

This case is similar to the preceding. From (13) and (14):

$$
\delta \theta=A\left(i_{1}-i_{2}\right) \quad A=360 / \pi \text { for } \theta \text { in degrees }
$$




$$
\begin{array}{rlrl}
\delta t & =B\left(\cot i_{1}-\cot i_{2}\right) \sin i_{1} & B & =2 r_{1} / V_{1} \\
\sin i_{2} & =C \sin i_{1} & C & =r_{2} / r_{1}
\end{array}
$$

The value of $a$ is again determined by the fact that $V_{1}=8.00$ for a given value of $r_{1}$. The following quantities were used: $r_{1}=6320 ; V_{1}=8.00 \mathrm{~km} / \mathrm{sec}$., as under assumption (b). It follows that $\log a=3.3017-10$. For $r_{2}=6,270$, $V_{2}=7.875 ; \theta=1^{\circ}$ corresponds to $109.4 \mathrm{~km}$. $A=114.59 ; B=1580.0$ sec.; $C=0.99209$.

Since $i_{2}$ and $i_{1}$ do not differ much, the angles and cotangents in equations (19) and (20) must be taken as accurately as necessary for the given sines. It may be preferable, to consider that in

$$
1-C=\epsilon
$$

$\epsilon$ is a small quantity, and that with sufficient approximation

$$
i_{1}-i_{2}=\epsilon \tan i_{1} ; \quad \delta \theta=114.59 \epsilon \tan i_{1} ;
$$

as long as $2 \epsilon$ is small compared with $\cos ^{2} i$

$$
\cot i_{1}-\cot i_{2}=\epsilon / \sin i_{1} \cos i_{1} ; \quad \delta t=B \epsilon / \cos i_{1}
$$

Under the assumptions made above, $\delta \theta=0.906 \tan i_{1} ; \delta t=12.50 / \cos i_{1}$ (for $i_{1}<70^{\circ}$ ). Results of the calculations are again given in table 5 .

Assumption $(d)$ : The velocity remains constant between $r_{1}$ and $r_{2}$ and decreases suddenly from $V_{1}$ to $V_{2}$ at the level with the radius $r_{2}$. Equations (1) to (3) could be used between $r_{1}$ and $r_{2}$, but the errors in calculation approach the errors in observations. It is therefore preferable to use the accurate equations (for $n=0$ ):

$$
\begin{aligned}
& \sin i_{2}=a \sin i_{1} \quad a=r_{1} / r_{2} \\
& \sin i_{3}=\frac{V_{2}}{V_{1}} \sin i_{2}=\frac{r_{1} V_{2}}{r_{2} V_{1}} \sin i_{1}
\end{aligned}
$$

$i_{2}=$ angle of incidence from above at the level $r_{2}, i_{3}$ from below. From (13) and (14):

$$
\begin{aligned}
& \delta \theta=2\left(i_{2}-i_{1}\right) \\
& \delta t=2 p\left(\cot i_{2}-\cot i_{1}\right)=2 r_{1} \sin \left(i_{2}-i_{1}\right) / V_{1} \sin i_{2}
\end{aligned}
$$


As long as $\delta \theta$ is small absolutely as well as compared with $(90-i)$, with sufficient approximation

$$
\delta \theta=2(a-1) \tan i_{1} \text { radians }
$$

Frequently $\delta \theta$ is too large for the use of (30). It was assumed that $r_{1}=6,330$ $\mathrm{km}$., $r_{2}=6,290 \mathrm{~km}$., which give $a=1.00636 ; \theta=1^{\circ}$ at $r_{2}$ equals $109.7 \mathrm{~km}$; $V_{1}=8.00 \mathrm{~km} / \mathrm{sec}$. By the method of trial and error it was found that the assumption $V_{2}=7.794$ leads to results which closely correspond to the given conditions. Equation (30) gives $\delta \theta=0.7228 \tan i_{1}$ degrees.

\section{TABLE 5}

Veloctity of Longitudinal Waves at the Depth $d$ $(J=$ Jeffreys, 1939; GR = Gutenberg-Richter, 1939b; MD = Macelwane-Dahm in Macelwane, 1939, p. 270.)

\begin{tabular}{|c|c|c|c|c|c|c|c|}
\hline \multirow{3}{*}{$d$} & \multicolumn{7}{|c|}{ Velocity, $\mathrm{km} / \mathrm{sec}$} \\
\hline & \multicolumn{4}{|c|}{ Assumption } & \multirow{2}{*}{$\mathbf{J}$} & \multirow{2}{*}{ GR } & \multirow{2}{*}{ MD } \\
\hline & (a) & (b) & (c) & (d) & & & \\
\hline $\begin{array}{l}\text { km. } \\
200\end{array}$ & 8.1 & 8.2 & 8.1 & 8.1 & 8.3 & 8.1 & 8.3 \\
\hline 250 & 8.3 & 8.4 & 8.3 & 8.4 & 8.5 & 8.4 & 8.5 \\
\hline 300 & 8.6 & 8.6 & 8.6 & 8.7 & 8.6 & 9.0 & 8.7 \\
\hline 350 & 8.8 & 8.9 & 8.8 & 9.0 & 8.8 & 9.3 & 8.9 \\
\hline 400 & 9.1 & 9.2 & 9.1 & 9.3 & 9.1 & 9.6 。 & 9.1 \\
\hline 450 & 9.3 & 9.5 & 9.3 & 9.6 & 9.3 & 9.8 & 9.4 \\
\hline 500 & 9.6 & 9.7 & 9.6 & 9.8 & 9.6 & 10.0 & 9.6 \\
\hline 550 & 9.8 & 10.0 & 9.8 & 10.1 & 9.9 & 10.2 & 10.1 \\
\hline 600 & 10.1 & 10.2 & 10.1 & 10.3 & 10.2 & 10.4 & 10.1 \\
\hline 650 & 10.4 & 10.4 & 10.3 & 10.5 & 10.4 & 10.6 & 10.3 \\
\hline
\end{tabular}

No attempt has been made in the present investigation to calculate amplitudes using the adopted travel-time curves or the resulting velocities. The amplitudes at distances of a few degrees have been discussed previously (Gutenberg, 1945a); even approximate calculations must be based on the theory of rays refracted almost tangent to boundaries the use of which is very difficult. For the shadow zone, the theory is still more complicated and only partly developed (Pekeris, 1946). For the beginning of the second branch the results depend very delicately on the assumed travel times.

\section{Results for P Waves}

Calculated velocity-depth curves under assumptions (a) to (d) as well as some earlier curves are plotted in figure 5 for the critical range in depth. In general, the absolute values do not differ beyond the limits of errors in the observed 


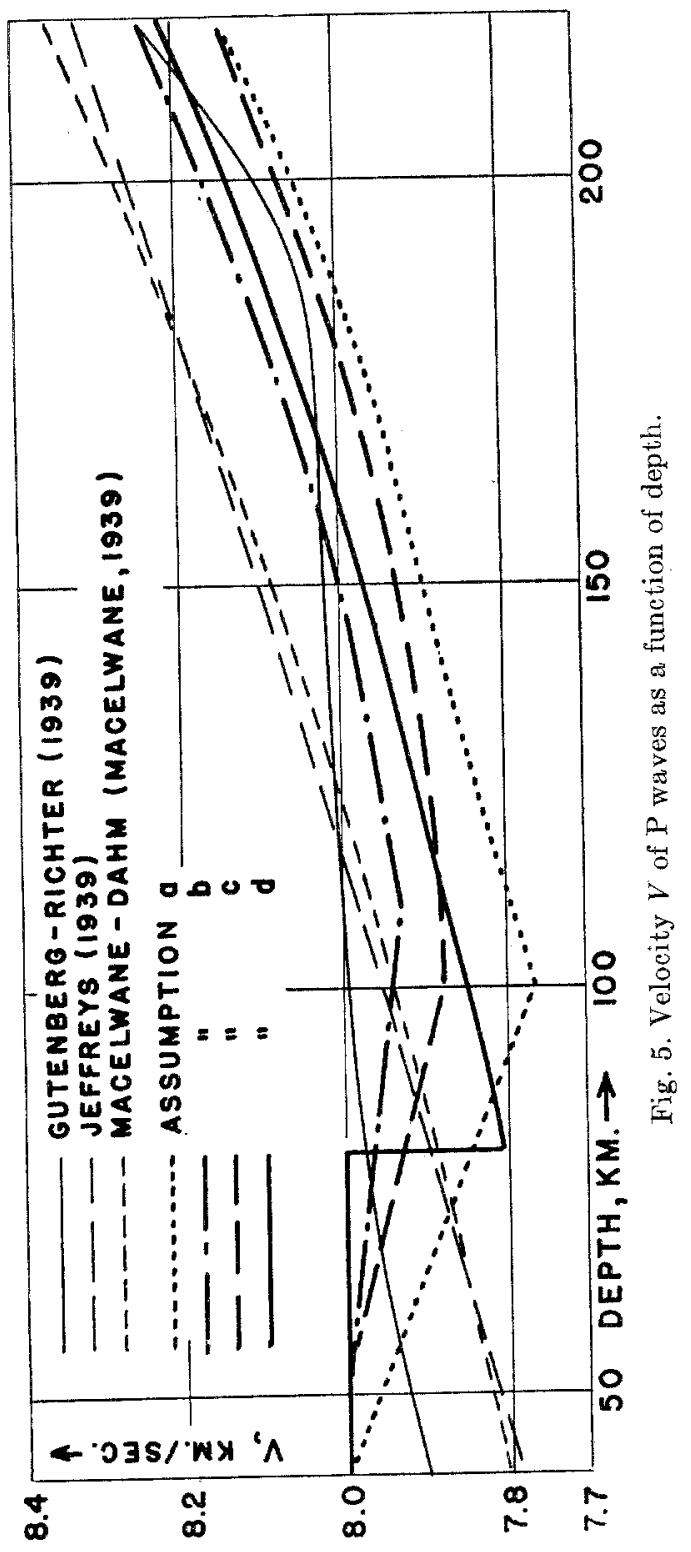




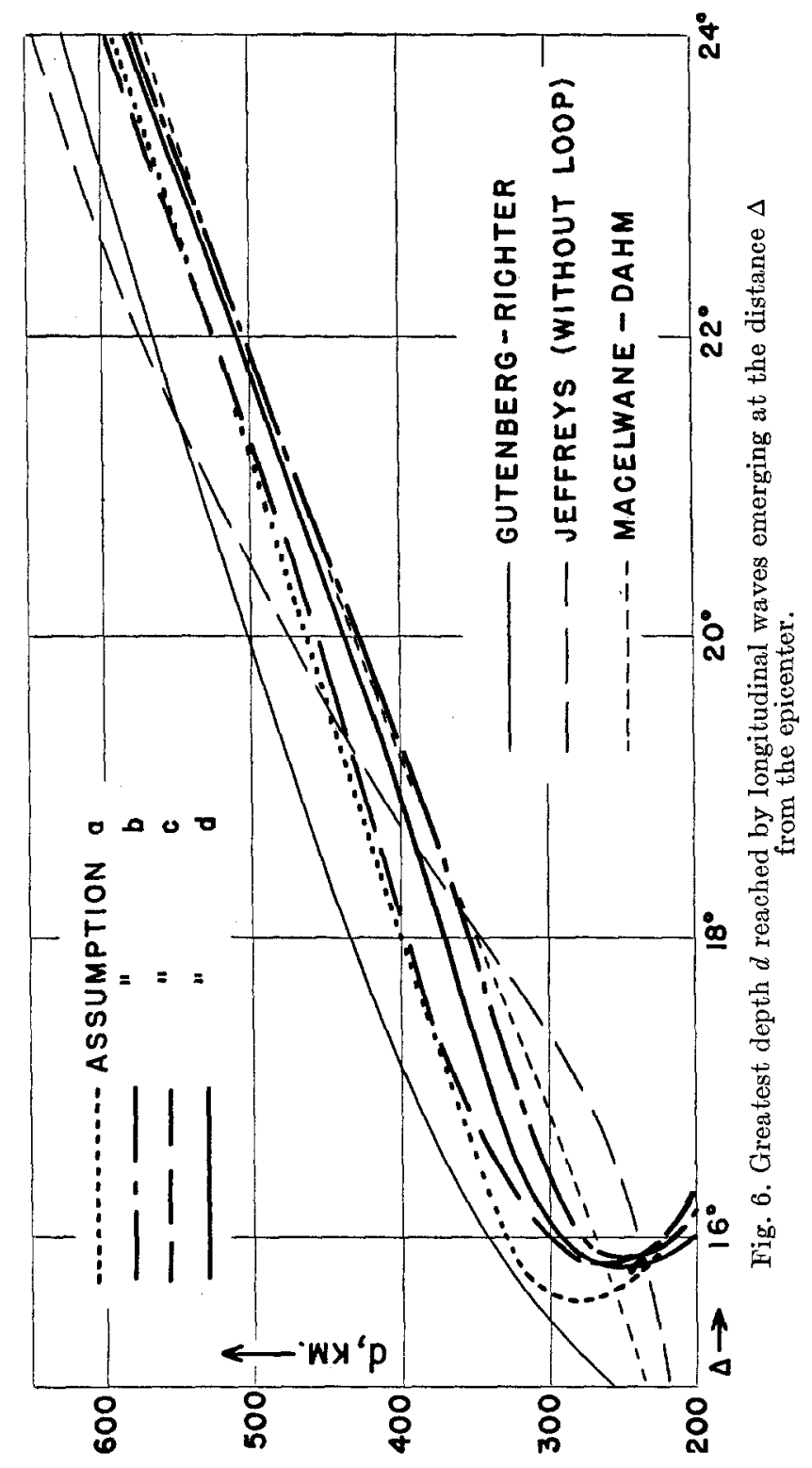


times. The differences between the four new curves are due not only to the different assumptions concerning the decrease in velocity, but also to slight differences (maximum $0.4^{\circ}$ ) in the distance at which the shadow zone begins. As this distance is not accurately known, no attempt was made to test more assumptions on the minimum velocity. Data on the velocity below $200 \mathrm{~km}$. are given in table 5 .

The new curves show that the velocity which prevails just above the layer with lower velocity is reached again at a depth of between 150 and $200 \mathrm{~km}$. Earthquakes with a focus at larger depth than this should not exhibit an actual shadow zone (Gutenberg-Richter, 1939a, p. 536). This agrees with the observations.

In figure 6 , the maximum depth is plotted which is reached by a ray arriving at a given distance $\Delta$ from the epicenter. The new curves show the effect of the shadow zone. No rays have their deepest point between the depth where the decrease in velocity downward begins and the depth where the maximum value above this layer is reached again. The first of these rays emerge at rather large distances $\Delta$ (with $d$ less than $200 \mathrm{~km}$.; they are not plotted in fig. 6). As the angle of incidence at the surface decreases, the maximum depth $d$ reached by the rays increases, first with decreasing $\Delta$, which reaches a minimum between $151 / 2$ and $16^{\circ}$ (end of shadow zone), then continues to increase, but now with increasing $\Delta$. Jeffreys (1939) has given two solutions, one with a loop corresponding to a cusp in the travel-time curve near $20^{\circ}$, and another without a loop. Only this second solution has been plotted in figure 6 , as no observations indicating such a loop have been encountered thus far.

\section{Matertals Used for S Waves}

The investigation of transverse waves is more difficult than that for longitudinal waves, for several reasons. First, the movement prevailing at the time of the $S$ waves, owing to late longitudinal and other waves, makes it difficult to find the beginning of $\mathrm{S}$ when its amplitude is small (called "curtsy" by Byerly). Second, the surface waves are frequently superimposed on the transverse waves at short distances, or follow soon after $\mathrm{S}$. Occasionally $\mathrm{S}$ is clearer on the vertical than on the horizontal component, owing to the later arrival of surface waves with a vertical component (Rayleigh waves). Third, at the auxiliary stations of the Pasadena group only short-period instruments are being used, and it is difficult to find the beginning of small, long-period transverse waves. At distances of more than $15^{\circ}$ the several long-period horizontal and vertical instruments at Pasadena frequently record S phases, with no indication of these phases on the short-period instruments. Fourth, for reasons unknown, not infrequently transverse waves are relatively poorly recorded in southern California, especially at Pasadena. Besides these difficulties, errors in the determination of epicentral distances produce a larger error in the calcu- 


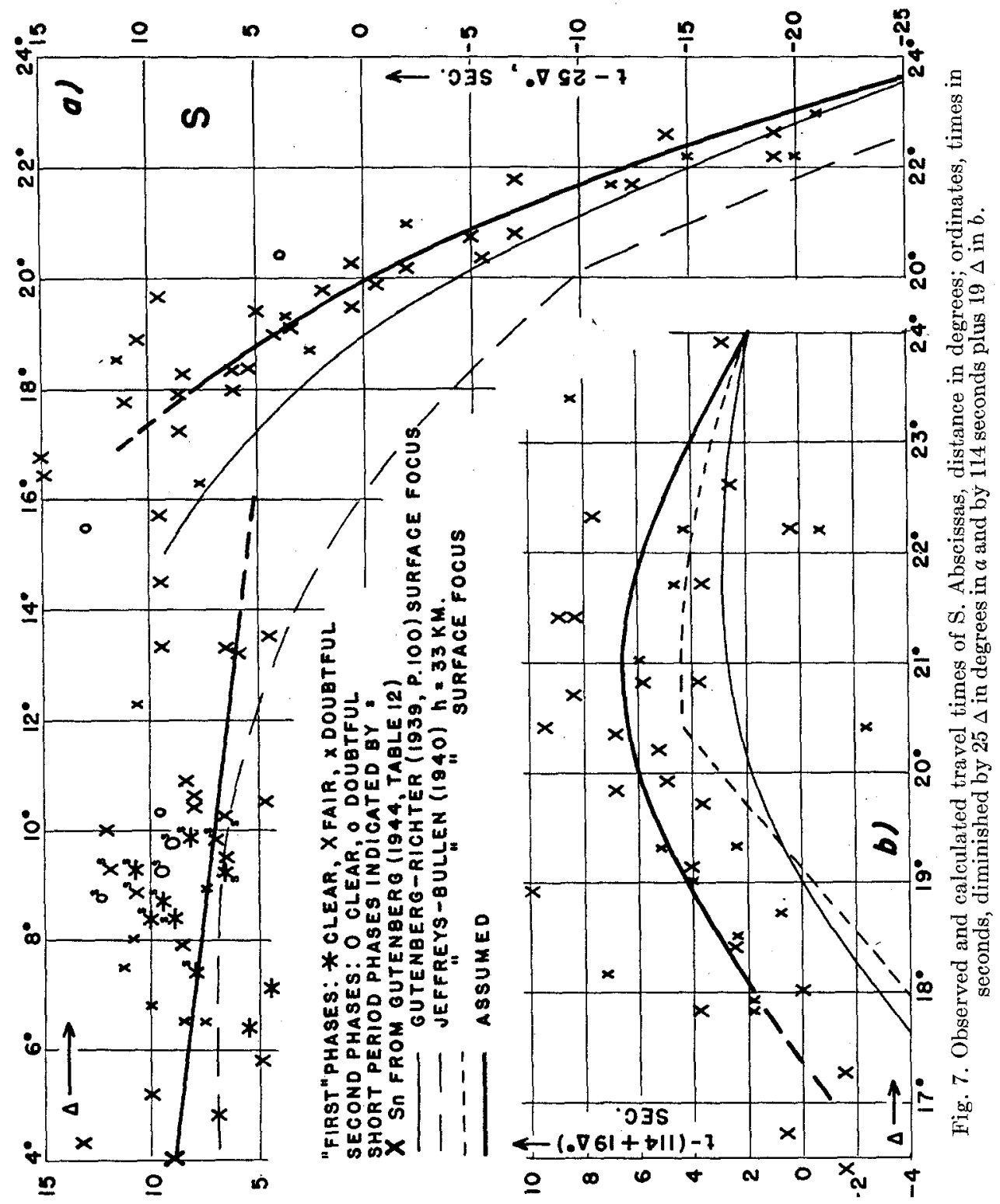




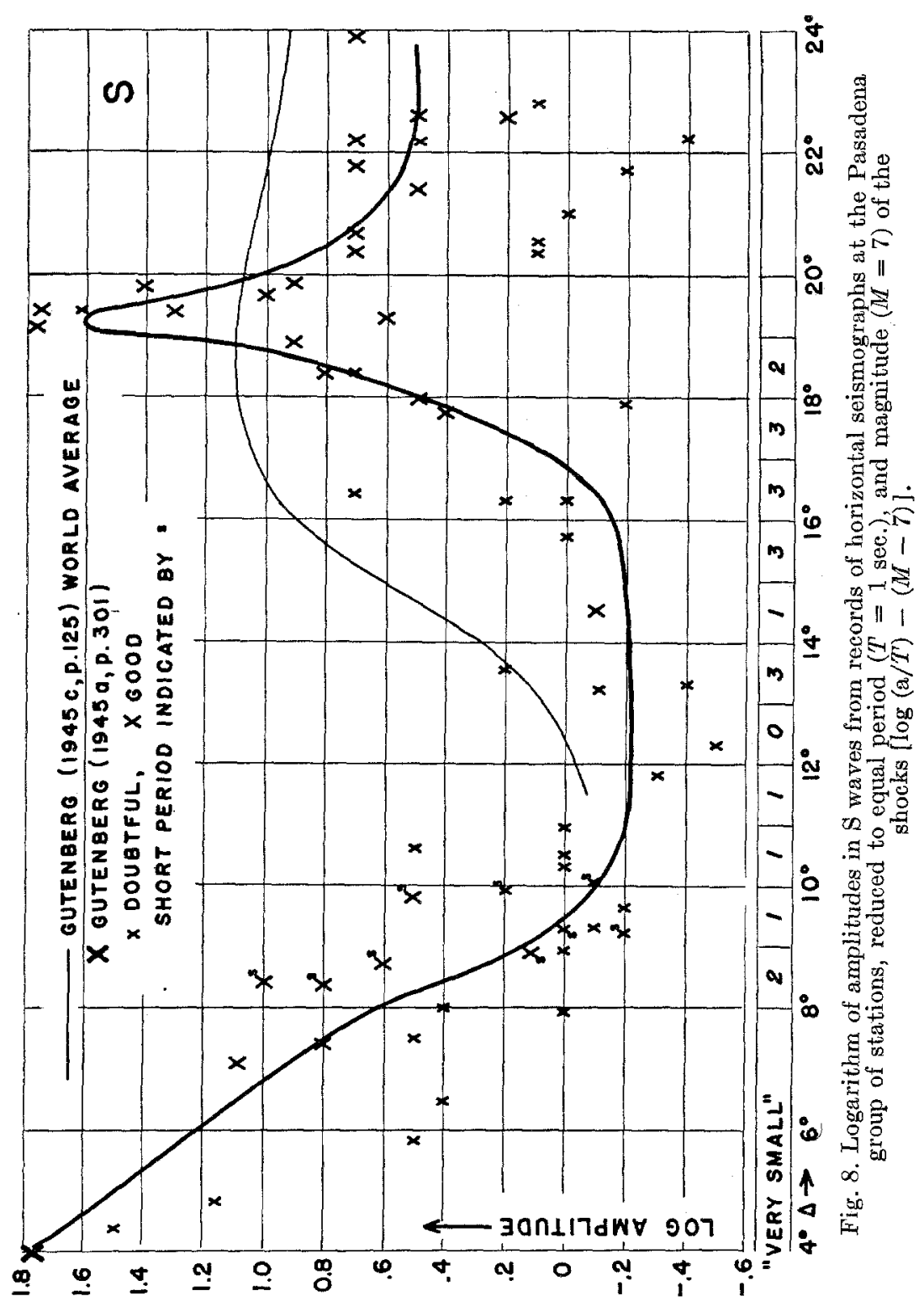


lation of the travel time of $\mathrm{S}$ from observations (about two seconds in time for each tenth of one degree in distance) than for $P$. In addition, the effect of differences in structure on the travel times of $S$ waves is larger than on those of $\mathrm{P}$ waves (Gutenberg, 1944a, p. 32). Consequently, a greater scattering of residuals is to be expected.

It has been found repeatedly that the beginning of the $\mathrm{S}$ phase is very doubtful and frequently "Iate" at distances between about $10^{\circ}$ and $20^{\circ}$ (Jeffreys,

TABLE 6

Assumed Travel Times $t$ of $S$ and Difzerences of S-P for Shocks at Normal Depth in Western North America

\begin{tabular}{|c|c|c|c|c|c|}
\hline \multicolumn{3}{|c|}{ First branch } & \multicolumn{3}{|c|}{ Second branch } \\
\hline$\underset{(d e g .)}{\Delta}$ & 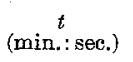 & $\underset{\text { (min.: sec.) }}{\mathrm{S}-\mathrm{P}}$ & $\begin{array}{c}\Delta \\
\text { (deg.) }\end{array}$ & ${ }_{(\min .: \mathrm{sec})}$ & $\begin{array}{c}\text { S-P } \\
\text { (min.: sec.) }\end{array}$ \\
\hline 5 & $2: 13$ & $0: 57$ & 17 & $7: 16$ & $3: 15$ \\
\hline 6 & 38 & $1: 08$ & 18 & 38 & $3: 25$ \\
\hline 7 & $3: 03$ & $1: 19$ & 19 & 59 & $3: 35$ \\
\hline 8 & 28 & $1: 30$ & 20 & $8: 20$ & $3: 44$ \\
\hline 9 & 52 & $1: 41$ & 21 & 40 & $3: 53$ \\
\hline 10 & $4: 17$ & $1: 52$ & 22 & 58 & $4: 01$ \\
\hline 11 & 42 & $2: 03$ & 23 & $9: 15$ & 4:08 \\
\hline \multirow[t]{2}{*}{12} & $5: 07$ & $2: 14$ & & & \\
\hline & & & 24 & 32 & $4: 15$ \\
\hline 13 & 31 & $2: 25$ & 25 & 49 & $4: 22$ \\
\hline 14 & 56 & $2: 36$ & 26 & $10: 05$ & $4: 28$ \\
\hline 15 & $6: 21$ & $2: 47$ & & & \\
\hline 16 & 45 & $2: 57$ & & & \\
\hline
\end{tabular}

1937, pp. 25-26; Jeffreys and Bullen, 1935, p. 40; Lehmann, 1934, p. 35). Lehmann considers that "there is likely to be a layer, in which there is a decrease in the velocity of the $\mathbf{S}$ waves," as she could not find normal $\mathrm{S}$ waves at distances of around $15^{\circ}$ in two earthquakes which she studied in detail. At short distances other complications occur, such as the "false S" of Byerly (1937) and the "short-period S" at distances between about $8^{\circ}$ and $10^{\circ}$ (Gutenberg and Richter, 1934, p. 99; 1935, p. 341). Observations of $\mathrm{S}$ with periods of about 1 sec. or less have been marked in figures 7 and 8 . They agree fairly well with the results from $S$ waves with larger periods.

Observed travel times of $\mathrm{S}$ have been plotted in figure 7. In figure 7, a, residuals are given as a function of distance relative to the straight line $t=25$ times the distance in degrees; and in figure 7, $b$, against the straight line $t=114$ seconds plus 19 times the distance in degrees. As in figure 2, travel-time curves of Jeffreys and Bullen (1940) and of Gutenberg-Richter (1939b) have been 


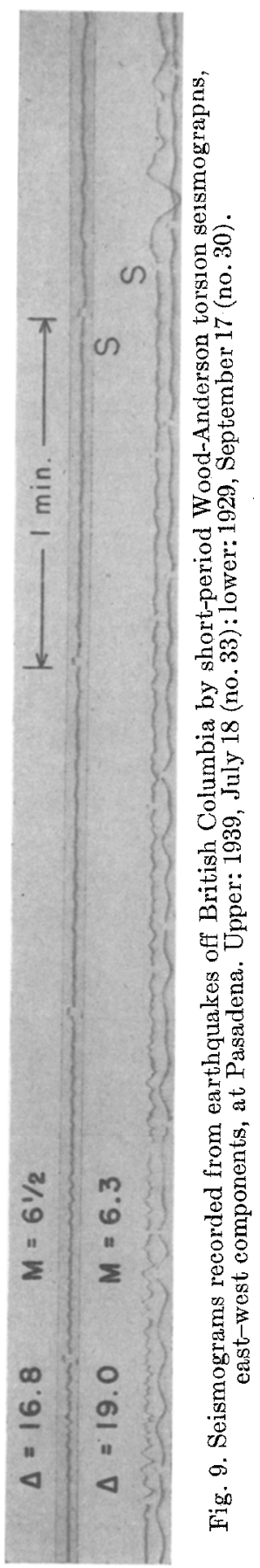


added, and similar remarks hold here, as in the case of $\mathrm{P}$. There are two branches of $\mathrm{S}$, corresponding to those of $\mathrm{P}$. The first, again; is practically a straight line (see also Stoneley, 1931, p. 356), suggesting a diffracted wave. Adopted travel times for $\mathrm{S}$ are given in table 6.

There is no doubt that, in shocks in the region considered here, $\mathrm{S}$ near $18^{\circ}$ arrives many $(10 \pm)$ seconds later than is indicated by the travel-time curves now in use. The procedure used by Gutenberg and Richter (1939b) and by Jeffreys (1939) to adjust travel times of $S$ in shallow shocks from observed travel times in deep shocks leads to errors, as at distances near $\Delta=18^{\circ}$ the travel times in shallow shocks are much affected by the low-velocity layer. On the other hand, observations of $\mathrm{S}$ between $19^{\circ}$ and $26^{\circ}$ tabulated by Gutenberg and Richter (1934, table 12, p. 97) agree fairly well with table 6.

Observed amplitudes are plotted in figure 8 . The shadow zone clearly extends to about $18^{\circ}$, and the increase in amplitudes of the $S$ waves at about $18^{\circ}$ (focal point?) is even more distinct than for P. Two examples showing the difference before and near the "focal point" are given in figure 9 . In instances where the amplitudes of the $\mathrm{S}$ waves were very small, and doubtful, owing to the movement preceding $\mathbf{S}$ or to surface waves, so that they could not be measured, they were marked as "very small"; the number of such instances per degree distance is given at the bottom of figure 8 . In determining the average amplitudes of $\mathrm{S}$ at a given distance these numbers should be considered. Between $18^{\circ}$ and $19^{\circ}$, frequently, a larger impulse follows a small beginning. $\mathrm{S}$, more frequently than $\mathrm{P}$, begins with small amplitudes and increases with time. In larger shocks this may be connected with the mechanism of the earthquake which requires a longer time for the fracturing over a greater distance than in small shocks. In such instances it is difficult to decide which amplitude should be measured. Occasionally the phase considered to be S may well have been another, more complicated phase.

The combined figures 7 and 8 leave no doubt that in the region of western North America the shadow zone for $S$ extends out to a larger distance than for $P$, at least by 3 degrees.

From the records of the Wenner seismographs at Huancayo, Peru, the amplitudes and periods of $\mathrm{S}$ were determined for a number of shocks with epicentral distance between $4^{\circ}$ and $24^{\circ}$ and a variety of focal depths. The quantity $A=M-\log (a / T)$ was calculated and plotted in figure 10 , similar to figure 4 for longitudinal waves. At the bottom of figure 10 the corresponding adopted values for the North American shocks discussed above are given. Comparison of figure 10 with figure 4 shows that the shadow zone occuring in $S$ waves extends farther out than that for $P$, in agreement with the results obtained from the North American shallow shocks. However, in the region of Huancayo it is relatively less intense for the $\mathrm{S}$ than for $\mathrm{P}$ waves, while near the Pacific coast of North America this is reversed. It is probable that the 


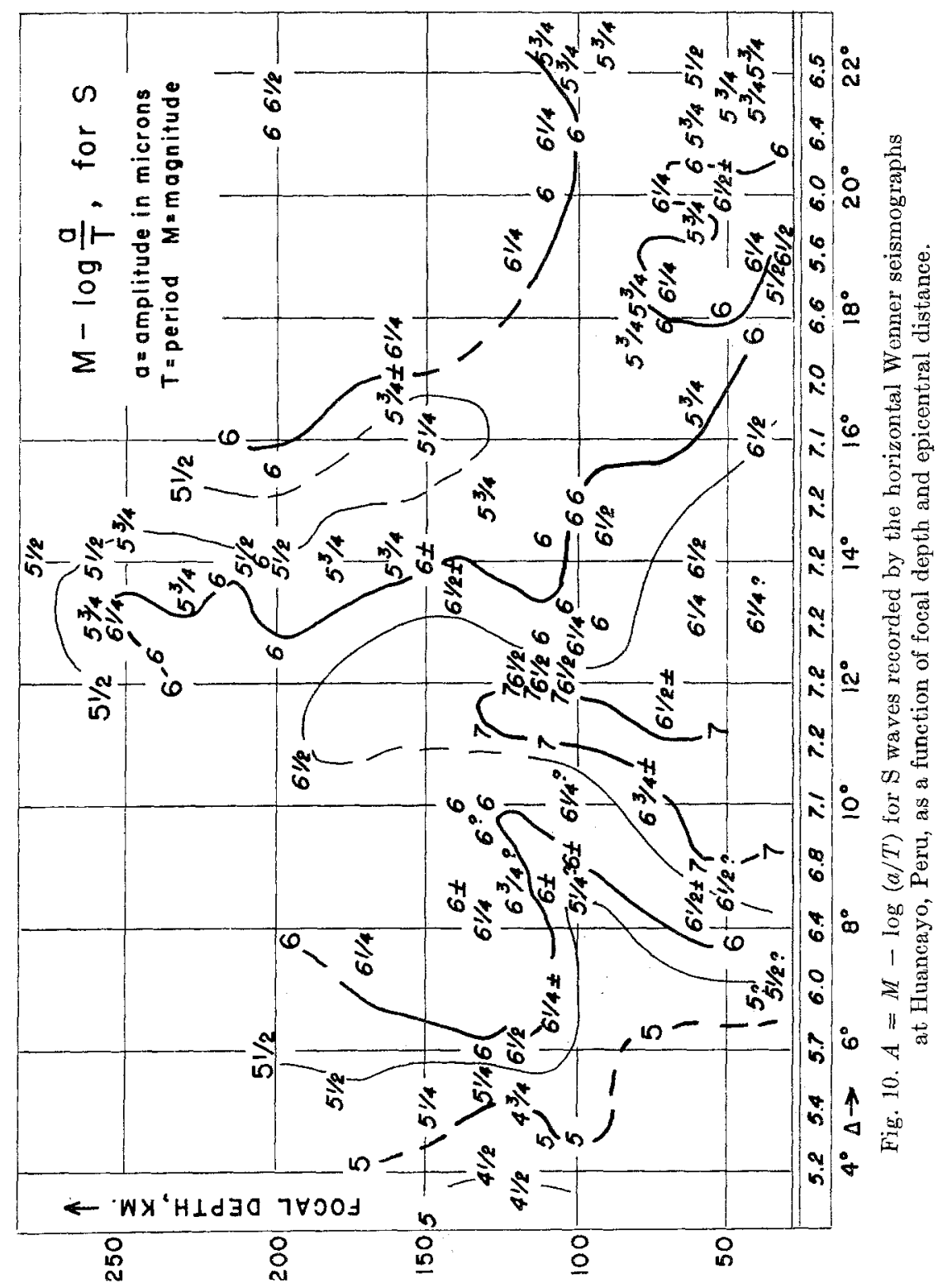


different behavior is mainly due to differences in crustal structure; but the use of different kinds of instruments, with maximum magnification for waves with periods of less than 1 second at the auxiliary stations of the Pasadena group, and maximum magnification for waves with periods near 7 seconds for the Huancayo Wenner instruments, may play some role. The first emphasize P, the second the $\mathrm{S}$ waves. In addition, phases arriving soon after $\mathrm{S}$ with larger amplitudes seem to have been mistaken for $\mathbf{S}$ in a number of instances. Examples of seismograms written at Huancayo, Peru, may be found in GutenbergRichter (1939a, fig. 1, p. 533).

\section{Calculations and Results for $\mathbf{S}$ Waves}

Calculations for $\mathrm{S}$ waves were made, similar to those for $\mathrm{P}$ waves. Travel-time curves reduced to a depth of $40 \mathrm{~km}$. were calculated. It was assumed that from 40 to $80 \mathrm{~km}$. the velocity of $\mathrm{S}$ waves is constant, $4.46 \mathrm{~km} / \mathrm{sec}$.- this value

TABLE 7

VELOCITY OF S-WAVES

\begin{tabular}{c|c||c|c}
\hline \hline $\begin{array}{c}\text { Depth } \\
(\mathrm{km} .)\end{array}$ & $\begin{array}{c}\text { Velocity } \\
(\mathrm{km} / \mathrm{sec})\end{array}$ & $\begin{array}{c}\text { Depth } \\
(\mathrm{km} .)\end{array}$ & $\begin{array}{c}\text { Velocity } \\
(\mathrm{km} / \mathrm{sec} .)\end{array}$ \\
\hline $0-18$ & 3.26 & 350 & 4.80 \\
$18-33$ & 3.64 & 400 & 4.95 \\
$33-40$ & 4.08 & 450 & 5.11 \\
$40-80$ & 4.46 & 500 & 5.28 \\
& & & \\
$80-120$ & 4.44 & 550 & 5.45 \\
150 & 4.46 & 600 & 5.62 \\
200 & 4.50 & 650 & 5.80 \\
250 & 4.58 & 700 & 5.96 \\
300 & 4.68 & 750 & 6.11 \\
\hline
\end{tabular}

corresponds to the slope of the first branch of the $S$ waves in figure $7 a$-and that at a depth of $80 \mathrm{~km}$. the velocity decreases suddenly. By the method of trial and error similarly as under assumption (d) for $\mathrm{P}$ it was found that in this case a velocity of $4.44 \mathrm{~km} / \mathrm{sec}$. just below $80 \mathrm{~km}$. must be assumed in order to explain the adopted travel times, as well as the shadow zone with a focal point at a distance of about $18^{\circ}$. Calculations were also made on the assumption that the revised travel-time curve of Gutenberg-Richter (1939b) for zero focal depth (fig. 7) actually represents the travel times of $\mathbf{S}$ for normal focal depth (18 km. in southern California). However, no velocity-depth curves could be found leading to these travel times and giving at the same time the observed shadow zone. It seems that the adopted travel-time curve of $\mathrm{S}$ is too early near $\Delta=18^{\circ}$ rather than too late. No attempts were made to assume 
a gradual decrease in the velocity of $\mathbf{S}$ with depth similar to the assumptions (a), (b), or (c) (fig. 5), but there is no doubt that the travel times and amplitudes of $\mathrm{S}$ can be explained within the limits of observational errors by assuming a gradual decrease of velocity with depth.

Calculated velocities for $S$ are given in table 7 . In general they agree with other recent values within $0.1 \mathrm{~km} / \mathrm{sec}$, which corresponds about to the accuracy with which the travel times are known. The rays emerging near the focal point at a distance of about $18^{\circ}$ penetrate to approximately $250 \mathrm{~km}$. The relationship between maximum depth $Z$ reached by a ray emerging at the surface at a distance $\Delta$ is given by a curve similar to those in figure 6 . Some characteristic values of the branch extending to greater distance are approximately as follows:

$\begin{array}{lrcrc}Z(\mathrm{~km} .) & 400 & 500 & 600 & 700 \\ \Delta(\mathrm{deg} .) & 19 & 201 / 2 & 22 & 241 / 2\end{array}$

As had to be expected from the relatively larger extent of the shadow zone for $\mathrm{S}$ than for $\mathrm{P}$ waves, Poisson's ratio seems to increase (gradually?) below a depth of $80 \mathrm{~km}$. It is slightly less than $1 / 4$ in the upper layers, about 0.30 between 200 and $300 \mathrm{~km}$., and, with slight variations, seems to remain between about 0.28 and 0.31 down to the surface of the core. The ratio $q$ of the coefficient of rigidity to the bulk modulus, depending only on Poisson's ratio $\sigma$, decreases correspondingly with depth. A few corresponding values are:

$\begin{array}{llllllll}\sigma \ldots \ldots \ldots \ldots & 0.50 & 0.30 & 0.28 & 0.25 & 0.23 & 0.20 & 0.125 \\ q \ldots \ldots \ldots \ldots & 0.00 & 0.46 & 0.52 & 0.60 & 0.66 & 0.75 & 1.00\end{array}$

\section{Summary and Conclusions}

Seismograms recorded at epicentral distances between $4^{\circ}$ and $26^{\circ}$ are investigated, and revised travel-time curves for $\mathrm{P}$ and $\mathrm{S}$ are given. Both consist of two branches, the first almost a straight line ending in a shadow zone, the second beginning with relatively large amplitudes and with a delay relative to the first branch. The end of the shadow zone for $\mathrm{P}$ seems to be near $15^{\circ}$ in most regions; for $\mathrm{S}$ this distance seems to vary somewhat and to be usually a few degrees greater. The "20-degree discontinuity" of Lehmann and Jeffreys, following Byerly (1926), as well as observations by Neumann (1933) and others, probably can be referred to the same phenomenon. Differences in distance are partly due to local effects, partly to the difficulty of tracing the first branch of the travel-time curves of $\mathrm{P}$ and $\mathrm{S}$ across the shadow zone.

Huancayo, Peru, seismograms from near-by earthquakes at intermediate depth are used for studying the change of amplitude with focal depth at a given distance in and near the shadow zone. All observations are explained on the assumption that the velocity of $\mathrm{P}$ as well as $\mathrm{S}$ waves decreases somewhat 
(between $1 / 2$ and 3 per cent?) at a depth below the Mohorovičić discontinuity to a minimum value at a depth near 80 to $100 \mathrm{~km}$. The data do not permit decision whether the decrease in velocity is gradual over a range of about $50 \mathrm{~km}$. or (almost) sudden at a given depth. The layer with lower velocity extends downward to a depth of about 150 to $180 \mathrm{~km}$.; below', the velocities increase rather rapidly, but Poisson's ratio remains near 0.30 , contrasting with a value of slightly less than $1 / 4$ in the upper layers. Correspondingly, the rigidity remains relatively small as compared with the bulk modulus, apparently down to the surface of the core.

It is of interest to note that such a low-velocity layer has now been established for the solid earth, the ocean, and the atmosphere, providing shadow zones for elastic (sound) waves in all three. It is also noteworthy that only a relatively small decrease in velocity is required to produce a rather extensive and pronounced shadow zone. The theory of free waves connected with the surface of minimum wave velocity probably will throw some light on the relatively large amplitudes and persistence of surface waves with a velocity of about $4.45 \mathrm{~km} / \mathrm{sec}$. in seismograms.

\section{REFERENCES}

Byerly, Perry

1926. "The Montana Earthquake of June 28, 1925," Bull. Seism. Soc. Am., 16:209-265.

1937. "Earthquakes off the Coast of Northern California," Bull. Seism. Soc. Am., $27: 73-95$.

BuLLEN, K. E.

1945. "Features of the Travel-time Curves of Seismic Rays," Monthly Not. Roy. Astron. Soc., Geophys. Suppl., 5:91-98.

Fu, C. Y.

1947. "On Seismic Rays and Waves," Bull. Seism. Soc. Am., 37:331-346.

Gutenberg, B.

1926. "Untersuchungen zur Frage, bis zu welcher Tiefe die Erde kristallin ist," Zeitschr.f. Geophysik, 2:24-29.

1928. "Der Aggregatzustand im Erdinnern," Müller-Pouillets Lehrbuch der Geophysik, 11 th ed., 5:669-671.

1944a. "Travel Times of Principal P and S Phases over Small Distances in Southern California," Bull. Seism. Soc. Am., 34:13-32.

1944b. "Reflected and Minor Phases in Records of Near-by Earthquakes in Southern California," Bull. Seism. Soc. Am., 34:137-160.

1945a. "Variations in Physical Properties within the Earth's Crustal Layers," Am. Jour. Science, Daly volume, 243-A: 285-312.

1945b. "Amplitudes of P, PP, and S, and Magnitude of Shallow Earthquakes," Bull. Seism. Soc. Am., 35:57-69.

1945c. "Magnitude Determination for Deep-focus Earthquakes,"' Bull. Seism. Soc. Am., 35:117-130. 
Gutenaerg, B., and C. F. Richten

1931. "On Supposed Discontinuities in the Mantle of the Earth, "Bull. Seism. Soc. Am., $21: 216-222$.

1934. "On Seismic Waves (First paper)," Gerlands Beitr. z. Geophys., 43:56-133.

1935. "On Seismic Waves (Second paper)," Gerlands Beitr. z. Geophys., 45:280-360.

1939a. "New Evidence for a Change in Physical Conditions at Depths near 100 Kilometers," Bull. Seism. Soc. Am., 29:531-537.

1939b. “On Seismic Waves (Fourth paper)," Gerlonds Beitr.z. Geophys., 54:94-136.

JeFFREYS, HAROLD

1936. "The Structure of the Earth Down to the $20^{\circ}$ Discontinuity," Monthly Not. Roy. Astron. Soc., Geophys. Suppl., 3:401-422.

1937. "The Structure of the Earth Down to the $20^{\circ}$ Discontimuity. (Second paper)," Monthly Not, Roy. Astron. Soc., Geophys. Suppl., 4:13-39.

1939. "The Times of P, S, and SKS, and the Velocities of P and S," Monthly Not. Roy. Astron. Soc., Geophys. Suppl., 4:498-533.

JEFFREYs, HAROLD, and K. E. BULIEN

1935. "Times of Transmission of Earthquake Waves," Publ. Bureau Central Séism. Internat., Traveaux Scientif., Ser. A, Fasc. 11, 106 pp.

1940. Seismological Tables, Brit. Assoc. Advancem. of Science, 48 pp.

LEHMANN, I.

1934. "Transmission Times for Seismic Waves for Epicentral Distances around 20"," Geodaetisk Institut København, Danmark, Meddelelse No. 5, 45 pp.

MaCelwane, James B.

1939. "Evidence on the Interior of the Earth Derived from Seismic Sources," Internal Constitution of the Earth (McGraw-Hill, New York), pp. 219-290.

MoHorovičíć, A.

1910. "Das Beben vom 8.X.1909," Jahrbuch. Meteor. Observ. Zagreb., Vol. 9, pt. 4, p. $1-63$.

NeumanN, Frank.

1933. "The Transmission of Seismic Waves," Trans. Am. Geophys. Union, pp. 329-335.

Peknris, C. L.

1946. "Theory of Propagation of Sound in a Half Space of Variable Sound Velocity under Conditions of Formation of a Shadow Zone," Jour. Acoust. Soc. Am., $18: 295-315$.

STONELEY, R.

1931. "Some Near Earthquakes Reported in the 'International Seismological Summary," Monthly Not. Roy. Astron. Soc., Geophys. Suppl., 2:349-362.

Californta Institute of Technology,

Pasadena, Calffornta.

(Balch Graduate School of the Geological Sciences, contribution no. 420.) 